\title{
Seismic Mitigation of a Historic Masonry Building
}

\author{
N.G. Maldonado*, P.E.Martín and I.A. Maldonado
}

CeReDeTeC, National Technological University, Regional Mendoza Faculty, Argentine

\begin{abstract}
This work presents an analysis of different proposals of rehabilitation of a masonry building, built around the beginning of the XX century for public schools, in the highest seismic risk zone of Argentine; and which was closed down after Mendoza`s Earthquake in 1985. The building has masonry walls of artisanal ceramic bricks and wood-framed roof but it does not have lateral ties. Currently, it gives evidence of structural pathologies due to various seismic events and the lack of maintenance by water losses. The work was developed in two stages, one in 1999, and the other one in 2010. At each stage, the evaluation of pathologies was carried out. Studies of the soil and the characterization of materials used were also conducted. As a reference, the effect of vibrations generated by the traffic was measured. With the parameters obtained, the structure was modeled through finite elements in order to verify the status of damage and the behavior of the proposed rehabilitation (reinforced concrete or steel structure). The technique of rehabilitation accepted by the heritage experts is the reversible type, in order to avoid further damage to the existing masonry. The seismic capacity is evaluated according to the rules in force. Both proposals should be considered as determining the site conditions and soils in relation to the vulnerability of construction and structural safety. The chosen solution has not only taken into account the use but also the service life of this intervention and the lowest cost possible with local technologies.
\end{abstract}

Keywords: Masonry, rehabilitation, preservation, soil capacity, seismic model.

\section{INTRODUCTION}

Bartolomé Mitre School was declared in the Cultural Heritage of the Province of Mendoza, Argentina by Decree $\mathrm{N}^{\mathrm{o}} 1617$ of in $01 / 10 / 1993$. The assessment as patrimonial architectural benefit is based in the documentary architectural appearance, the monumental appearance by its scarce typology and the possibility of extinction and the significant value for local society.

The style of the construction corresponds to the educative policy implemented by the Láinez Law (1905) in respect to the construction of monumental schools in all the national territory since it was necessary "to educate a sovereign" (Grementieri 2010) [1]. The project building of Mitre School began in 1888 , but it suffered the changes of political and economic crisis (1890) of the country, with long interruptions up to its opening in 1906.

The building is designed specifically for school purposes (Fig. 1); it has one level on a cloistral diagram or central square playground (Fig. 2), surrounded by galleries where the classrooms doors open to the main front. There is a second playground with another block of classrooms and a third one with sanitary services.

By 1957, the terrain of the south playground was sold, closing the openings and losing the natural light of the classrooms in the south side. The distinct interventions during its service life, more of than 70 years, improved its original be-

*Address correspondence to this author at the Olegario Andrade 56 - Dorrego - Guaymallén - Mendoza - República Argentina, CP 5519 / Universidad Tecnológica Nacional, Facultad Regional Mendoza, Centro Regional de Desarrollos Tecnológicos para la Construcción, Sismología e Ingeniería Sísmica (CeReDeTeC); Tel: 54261 5244552; Fax: 54261 5244551;

E-mails; romanarq@yahoo.com.ar; ngm@frm.utn.edu.ar havior but they aggravated the habitability problems (Maldonado PEC 2000) [2].

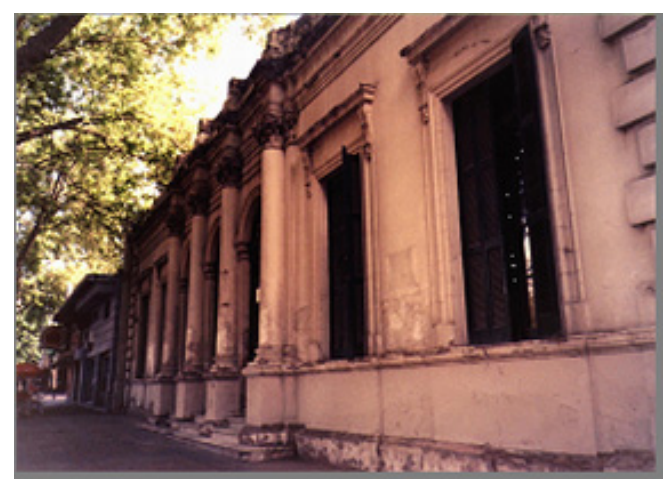

Fig. (1). State of the facade in 1999.

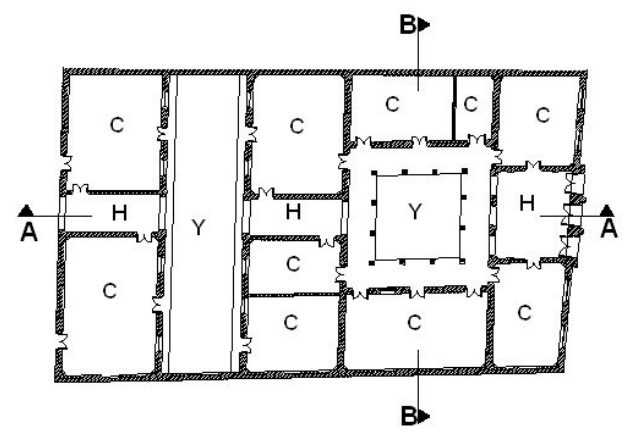

Fig. (2). Floor plant (C: classroom, H: hall, Y: yard).

The Government of Mendoza Province is the owner of this building and it required the setting in value as an educa- 


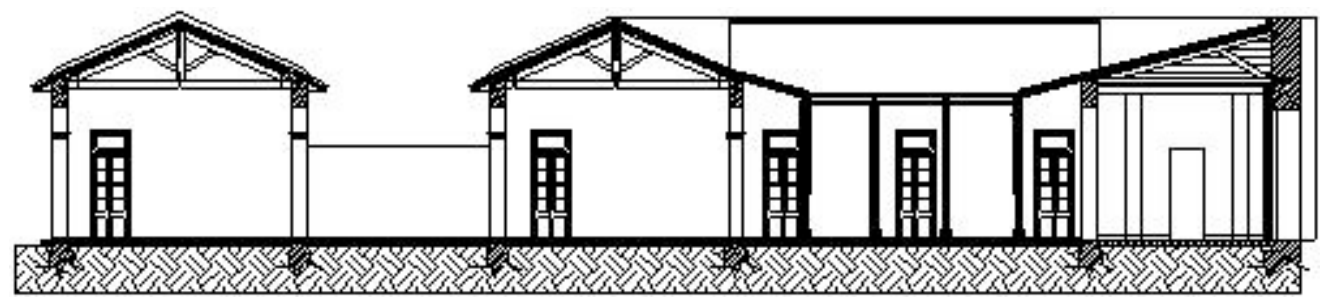

Fig. (3). A-A Vertical section of the building.

tive institution; thus, in 1999 it initiated the proper studies which continued during 2010. Fig. (2) presents the actual floor plant and Figs. (3) and (4) show vertical sections of building.

The methodology used to carry out the proposals included the following stages: detailed survey, emergency decisions, analysis of the conservation conditions of the building, diagnostic and proposal rehabilitation (Maldonado PIIJTRCP 2003) [3].

The structural rehabilitation of historical buildings could be done by hiding those new structural elements or exposing them. Sometimes, it is prefer the exhibition of new structural elements because alterations of this type may be reversible; in a future they can be changed without losing the historical character of the building.

The decision to hide or expose structural elements is complex and there is to be consensual with the professionals of the preservation which are participants of the project. In high seismic risk area it is difficult to strictly follow the principles of the different Restoration Charts (Venice, Athens, etc) and the task is a challenge of structural engineering (Cismigiu P11WCEE 1996) [4].

\section{MATERIALS AND METHODOLOGY}

The artisanal solid clay-brick unit masonry was identified, with its physical and mechanical properties (density, porosity, compressive strength in Fig. 5). And the ultimate capacities under simultaneous loads of compression and shear were evaluated in laboratory tests with specimens extracted from the building (Fig. 6). Table 1 resumes the obtained results.

The soil under the existing continuous footing (built with rubbish and stones with lime mortar $0.60 \mathrm{~cm} \times 0.90 \mathrm{~m}$ of depth) also was studied. The soils study allows to characterize the soil: the first $4.50 \mathrm{~m}$ are fine soils with plasticity, continuous and with a lot of moisture (CL) and underneath there are alluvial soils and semi-debris of very good forming soils (GP),which do not present discontinuities until the $-9.0 \mathrm{~m}$ analyzed, by means of exploration of open pit.

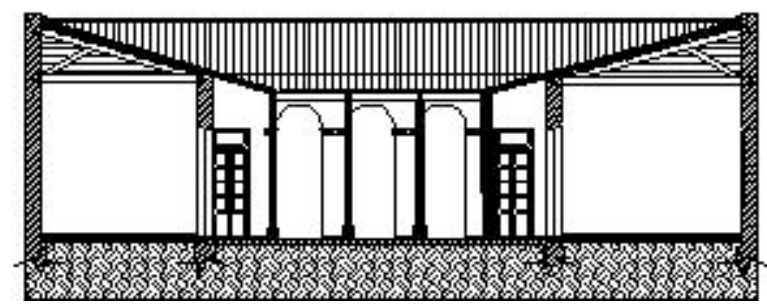

Fig. (4). B-B Vertical section of the building.
Moreover, it was measured the speed of shear wave (up hole test) which did not surpass the $200 \mathrm{~m} / \mathrm{s}$ at the first 4,50 $\mathrm{m}$ and from the $4.50 \mathrm{~m}$ to $9 \mathrm{~m}$ was of $365 \mathrm{~m} / \mathrm{s}$.

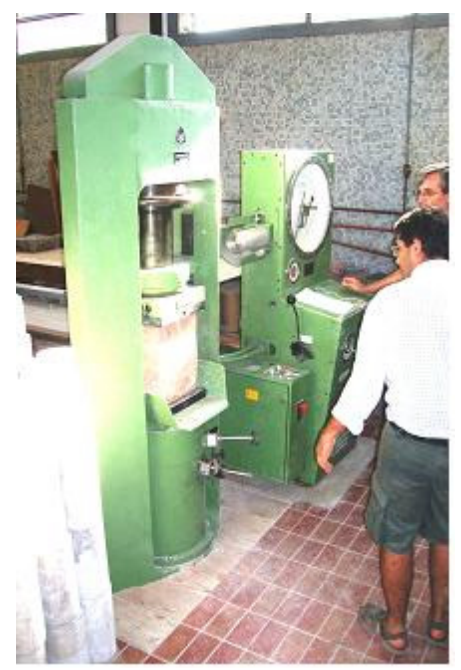

Fig. (5). Test set-up of the compression test.

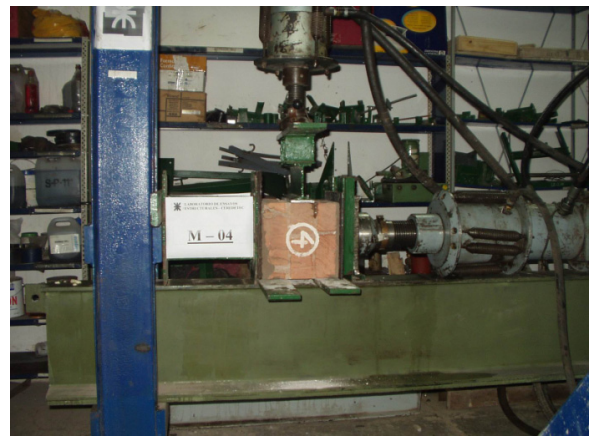

Fig. (6). Test set-up of combined compression and shear test of masonry.

The geotechnical parameters (Kv: coefficient of vertical subgrade reaction, Kh: coefficient of horizontal subgrade reaction, Eo: deformation modulus and Vs: shear wave velocity) were determined in a laboratory and fieldwork of samples extracted at different depths and from the plate load test (Table 2) and the results were used for modeling the behavior of the foundation.

In addition to standard tests for the identification of the materials used, some complementary studies for the detec- 
Table 1. Characteristics Materials

\begin{tabular}{|c|c|c|}
\hline Item & Unit & Value \\
\hline \hline Specific weight of artisanal solid-clay unit masonry (average) & $\mathrm{kg} / \mathrm{m}^{3}$ & 1653 \\
\hline Porosity of unit masonry (average) & $\%$ & $15-20$ \\
\hline Moisture of unit masonry (average) & $\mathrm{MPa}$ & 4 \\
\hline Compressive strength of unit masonry (average) & $\mathrm{MPa}$ & 2.5 \\
\hline Compressive strength of masonry & $\mathrm{MPa}$ & $0.242-0.478$ \\
\hline Compressive strength - shear strength of masonry & $\mathrm{MPa}$ & $0.494-0.805$ \\
\hline Compressive strength - shear strength of masonry & $\mathrm{MPa}$ & $1.098-0.972$ \\
\hline Compressive strength - shear strength of masonry & & \\
\hline
\end{tabular}

tion of metals and gamma-ray scan were done and they did not detect reinforcements.

The prospecting situated in the lintel did not indicate presence of reinforcement ties in the masonry structure (Fig. 7). Only tighteners in the centered zone of the principal hall were present, superficially situated as product of the first intervention to conform a tie-system of the building, but non enough to avoid the damage causes by seismic loading (Fig. 8).

\section{Table 2. Results of Performance Soils Tests}

\begin{tabular}{|c|c|c|c|c|}
\hline $\begin{array}{c}\text { Location in the soil } \\
\text { profile }\end{array}$ & $\mathbf{K v}$ & $\mathbf{K h}$ & $\mathbf{E o}$ & $\mathbf{V s}$ \\
\cline { 2 - 5 } & $\mathbf{k g} / \mathbf{c m}^{3}$ & $\mathbf{k g} / \mathbf{c m}^{3}$ & $\mathbf{k N} / \mathbf{m}^{2}$ & $\mathbf{~ m / s}$ \\
\hline \hline Layer 0 to $4.5 \mathrm{~m}$ & 3.23 & 1.62 & 7797 & 200 \\
\hline Layer 4.5 to $9 \mathrm{~m}$ & 8.88 & 4.40 & 25000 & 365 \\
\hline
\end{tabular}

An exhaustive exploration of the building pathologies was done, evaluating the damage during the decade between the first study and the last. One of the damages of the masonry owe to the Mendoza Earthquake of 1985, with cracks in the tympanum at $45^{\circ}$ (Fig. 9), and the separation of the

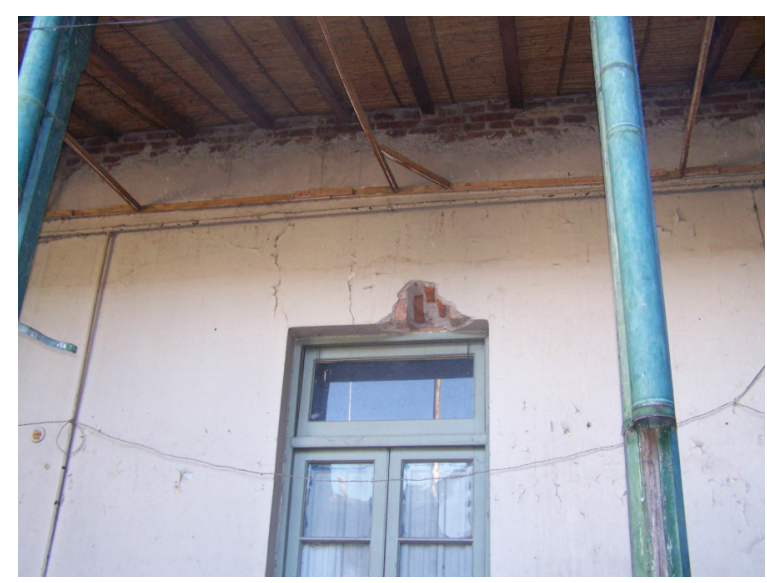

Fig. (7). Prospecting over openings. facade afterwards 2005 and 2006 earthquakes (Maldonado WHE 2008) [5] (Fig. 10).

Besides, some leach at floor level and at mid-high level in masonry walls, as a result of the absence of underlayment on the continuous footing and due to the modification of vent conditions by replacing the existing wood strip flooring for ceramic floor and the presence of several layers of oilpainting on the masonry walls, which prevent the evaporation of moisture (Fig. 11).

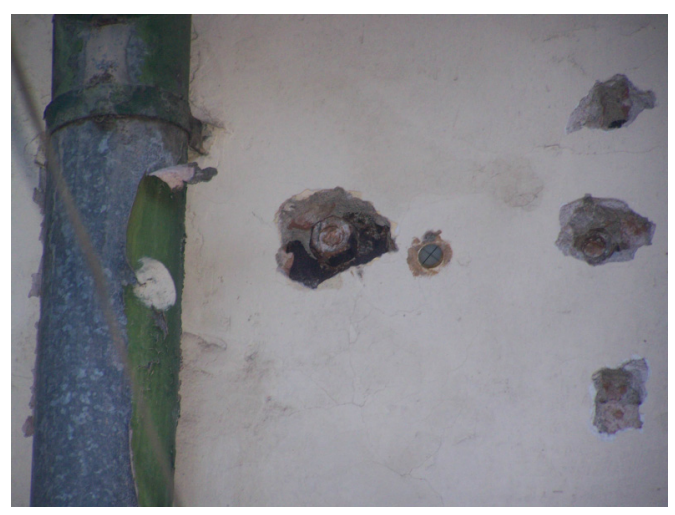

Fig. (8). Detected tighteners.

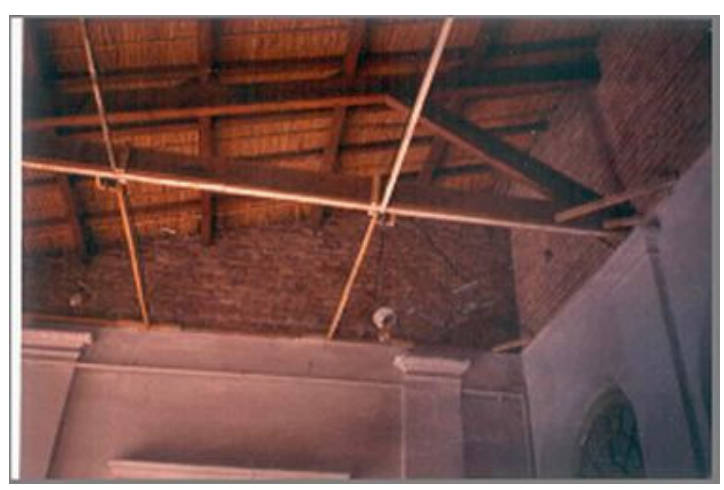

Fig. (9). Cracking of tympanus (1985). 


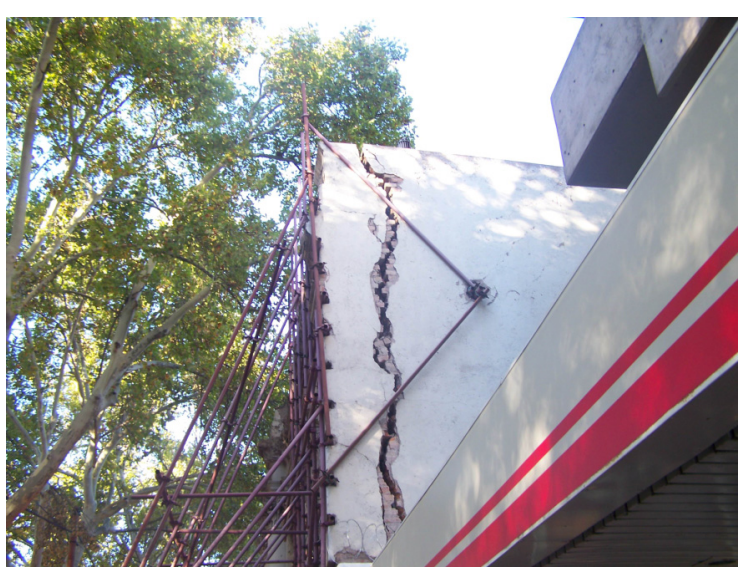

Fig. (10). Cracking of façade (2010).

The soils study detected permanent losses in the plumbing and drainage of rains, with the consequent increase of the moisture and cracking of masonry by settlements due the type of soil (CL) and the contribution of water by the use of facilities (Figs. 11, 12, 13 and 14).

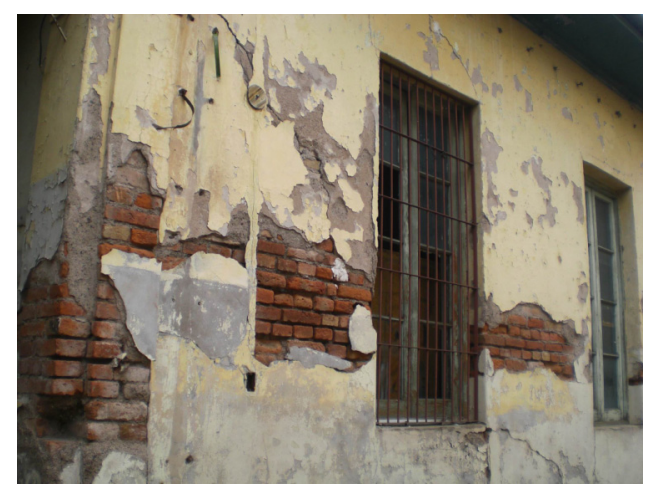

Fig. (11). State of masonry walls.

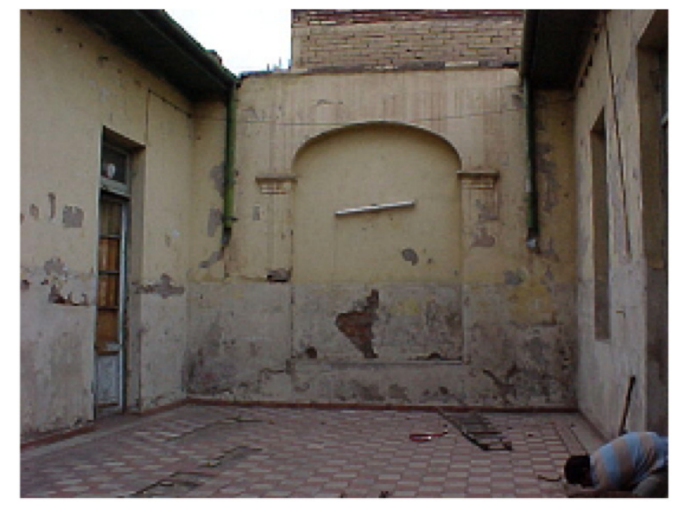

Fig. (12). Modifications of ventilations.

The study of environmental vibrations measured the effect of the diurnal traffic at different levels: floor and roof (Fig. 15) in 19 and 8 points respectively detecting an important transmission in all the masonry structure (Fig. 16).

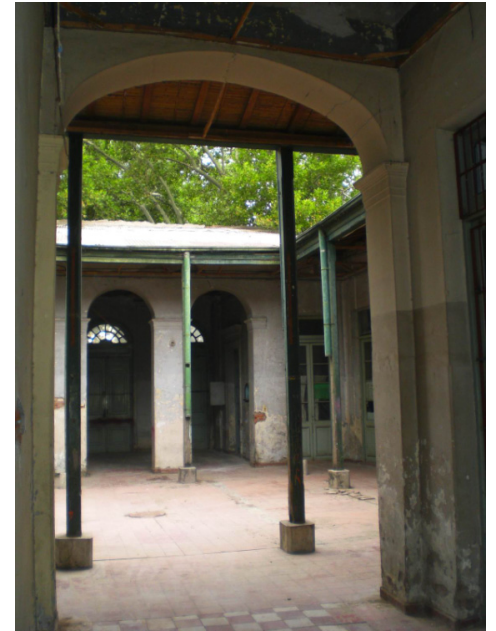

Fig. (13). Settlements of the soils.

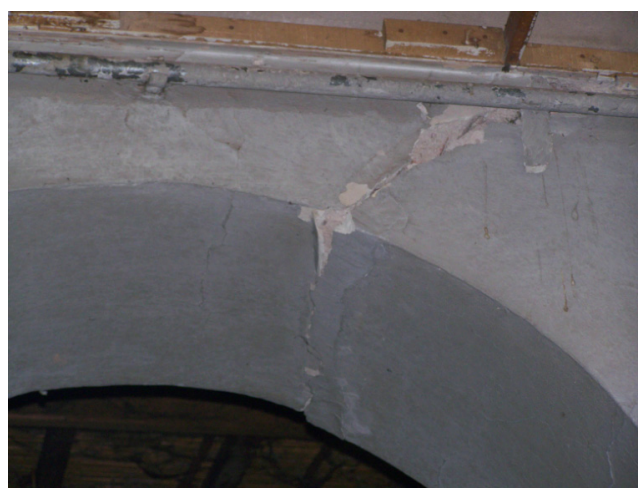

Fig. (14). Cracking of arches.

The structure and the behavior of the soil under the continuous footing were modeled using the parameters obtained in site and laboratory tests for verifying the structural damage.

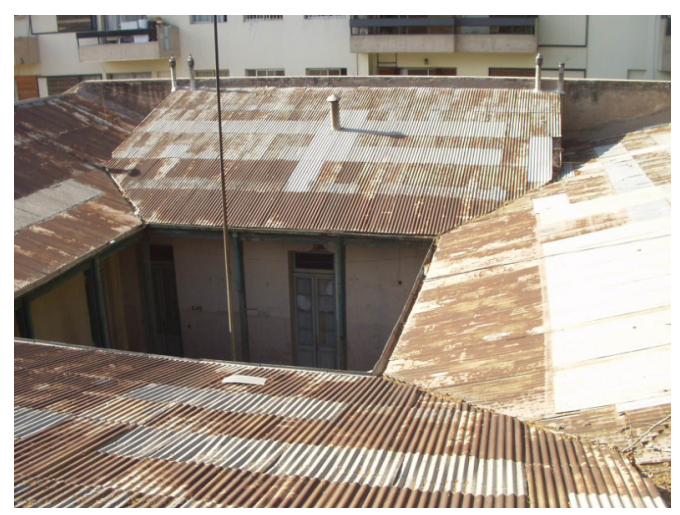

Fig. (15). View of the sheet roof covering.

\section{BEHAVIOR OF SOILS AND FOUNDATIONS}

Consequently, by means of the model of the building by finite element method, the charts of displacements for the 
maximum seismic action can be appreciated and they indicate the most vulnerable sectors of the building which coincide with the damaged sectors at present. It is very important to calculate the ultimate capacity of present foundations as system. For this purpose, an elasto-plastic Mohr Coulomb model with triangle elements of 15 nodes has been utilized (PLAXIS VB 2005) [6] for rigid foundations. In the 15 node triangular element, nodes are located one at each end of the triangle, three nodes on each side of the triangle and three nodes within the triangle. Fig. (17) presents the deformed finite element mesh. The model includes a pre-defined deformation of $0.02 \mathrm{~m}$. Fig. (10) on page 4 shows the actual cracking of masonry. The chosen value of deformation coincided with the value of the compatible deformation supported by this local masonry. Fig. (18) shows the variation of total displacements under foundation. Therefore, to obtain such deformation is necessary a pressure of $47 \mathrm{kN} / \mathrm{m} 2$. Confirming the reason of the cracking, results in Fig. (19) show that the current value of pressure under the masonry wall is between 112 and $115 \mathrm{kN} / \mathrm{m} 2$.

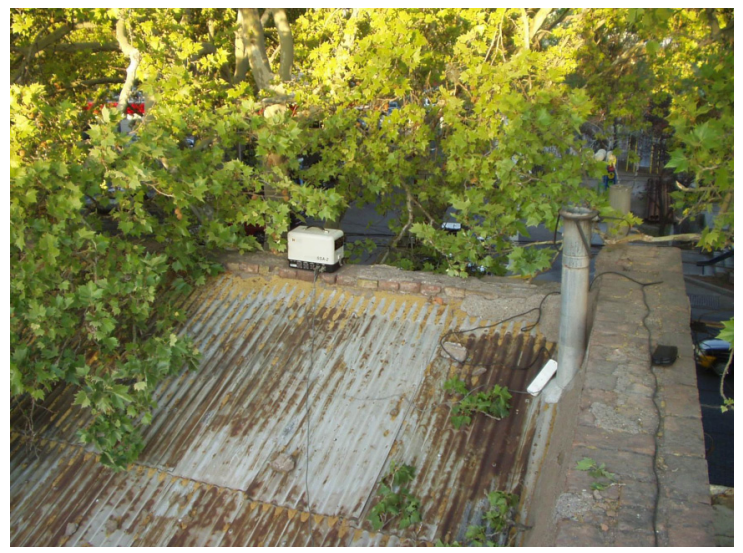

Fig. (16). Location of accelerometer.

The observed damages in the building correspond not only to the problem of 1985 Mendoza Earthquake and the later important earthquakes but also to the lack of support capacity of the soil. The diagnostic indicates the need to reinforce the structural foundation system as a consequence to avoid displacements without compatibility with the unreinforced masonry structures (Fig. 10).

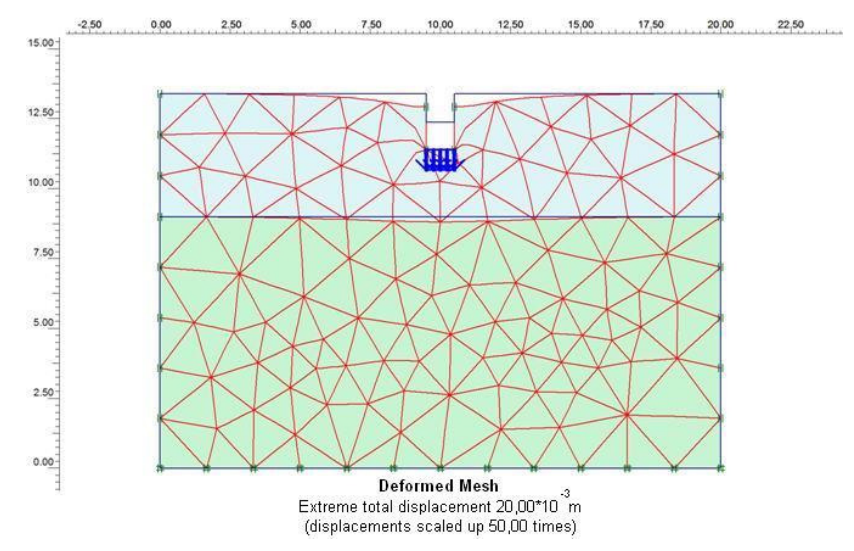

Fig. (17). Deformed finite element mesh of soil.
The proposal of structural design of restoration has to comply with two appearances:

- recover the monolithic performance of the building

- carry out the requests to ensure that the structure is safe under the local seismic level.

From the technical point of view the full restoration of seismic performance is feasible, but from the economic point of view it will be necessary to analyze the possible alternatives regarding costs.

\section{DISCUSSION AND RESULTS}

From the geotechnical point of view, it is necessary to improve the current state foundation or the load distribution of the foundations in order to attenuate the continuous cracking of masonry walls. The different methods of intervention correspond to superficial or deep improvement procedures or surrounding capacity improvement. The choice of one procedure or the other will be related to the knowledge of the art and to the local technology available (US Dep. Housing and Urban Development 1997) [7].

Taking into account the superficial improvement procedures can be chosen different alternatives: the reinforcement (when the area of support is sufficient but the foundation is not rigid), the extension (when the foundation is adequate and it well preserves but it does not have sufficient area of support) and the replacement (when neither the reinforcement nor the extension are viable alternatives).

The strengthening by pressure grouted injections would be ideal if the dimensions of the foundation had been properly designed so that the voids are filled with cement mortar. The reinforcement is not feasible by introducing steel minipiles because the bearing stratum is not sufficient and the foundations are degraded.

The extension is one of the most viable alternatives to take into consideration and it consists on broadening the foundation to increase the surface of contact with the ground, attaining an intervention almost imperceptible to the sight. The footing widening (whose interlocking) can be achieved by means of anchors, resins or the serrated joint contact. It is necessary to attain solid unity between the new concretes and the existing foundation using expansive mortars. Some attached footings could arise (acting in one or two sides). This type of intervention has as an advantage the reliability in the execution because the foundations are not undermined.

The method of replacement consists of a new foundation that substitutes the previous one, conserving or not the existing foundation. The foundation under masonry wall is by steps, with partial undermine of the foundation up to a level of resistant ground $(-4.50 \mathrm{~m})$ or where the displacements are tolerated. When the areas of the footings or extensions are important it may be consider the use of solid mat of reinforced concrete for the distribution of loads.

The improvement deep procedures imply a transfer of the loads to the nearest and most resistant strata which is in this case from $-4.50 \mathrm{~m}$ by piers, micro-piles or piles. For strengthening the foundation with piers it is necessary to arrange reinforced concrete piers in a strategic manner to carry the loads to the stiffer stratum (granular soils). To en- 


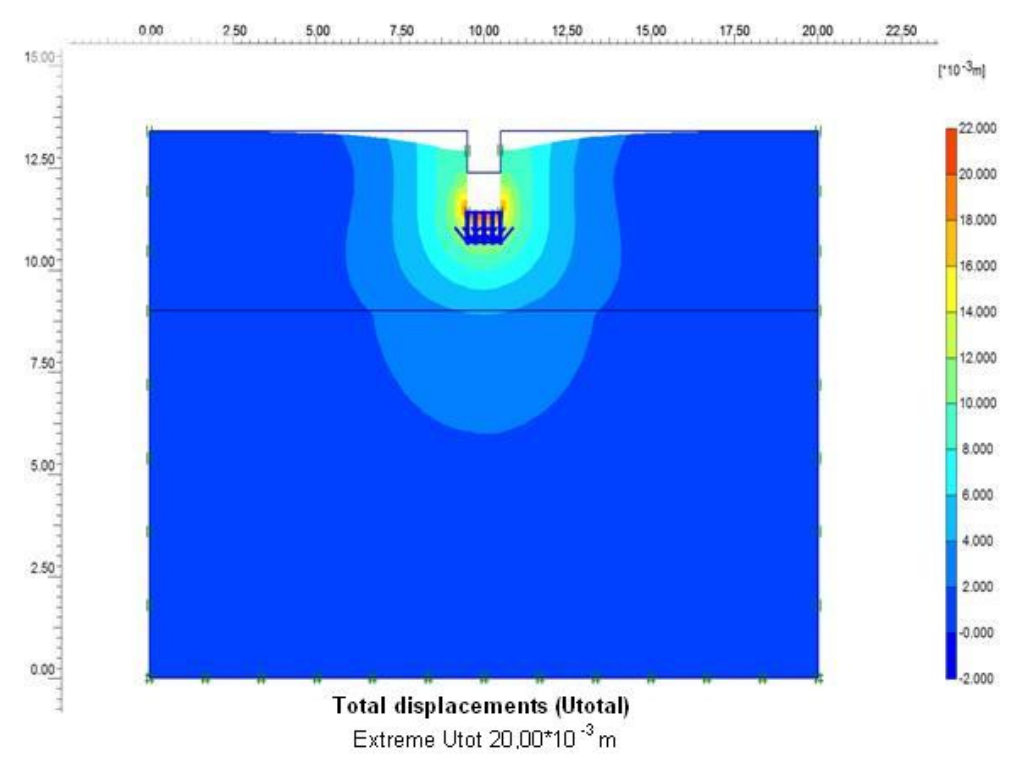

Fig. (18). Variation of the deformations in the soil profile.

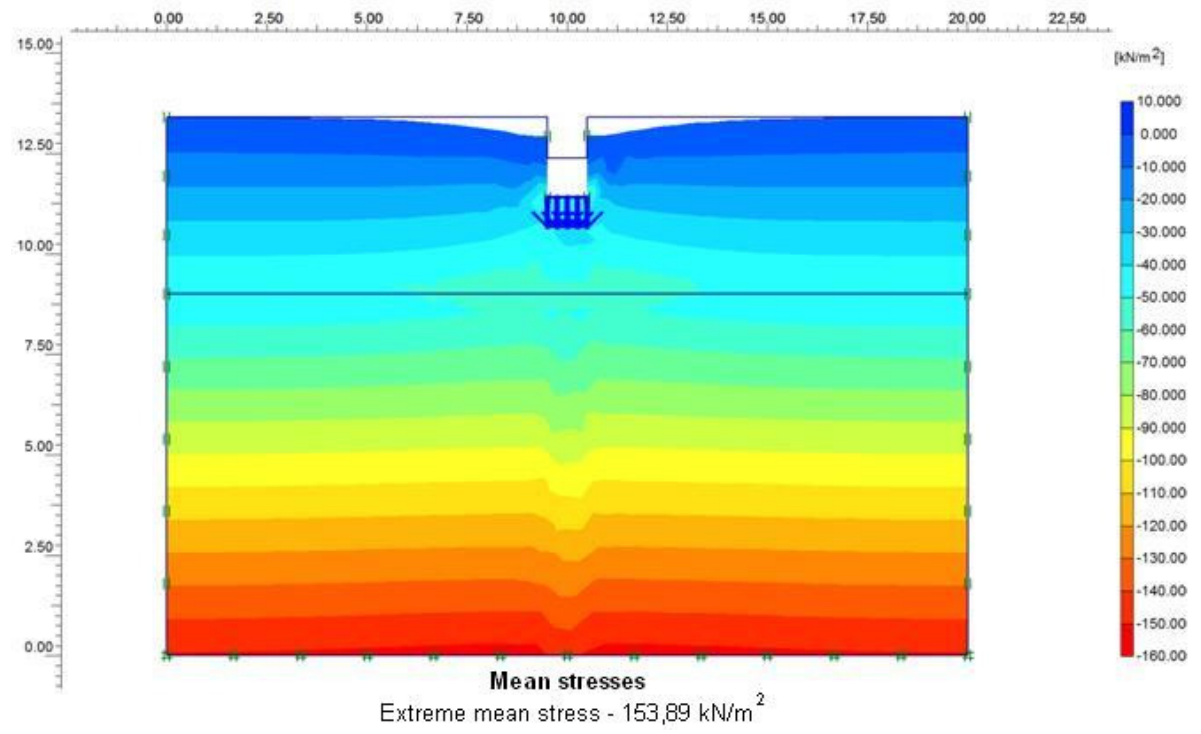

Fig. (19). Variation of the stresses in the soil profile under footing.

sure the replacement of the foundations it is also necessary to use rigid foundations beams which partially replace the foundations and link the head of the piers. For the calculation of the foundation beams are considered to support them rigidly at the top of piers in elastic manner on the plastic soil above (Fig. 20). The ultimate lateral load capacity of a pier defines a loading condition in which a pier can fail with the development of a plastic hinge (long pier) or by unlimited deflection (short pier). The Broms method (Broms J ASCE 1965) [8] can be used to compute the ultimate lateral resistance of small piers in cohesive and cohesionless soils as a function of the pier dimension, type of loading and fixity at the head. In general, the capacity of short piers is covered by soil failure while for long piers or piles, the capacity is governed by structural failure of the pier. Deflections can be computed using the Terzaghi theory of subgrade reaction by assuming a linear relationship between load and deflection.
An interesting option is the use of micro-piles (pilediameter between 100 and $300 \mathrm{~mm}$ ) which are very useful in the works of strengthening of foundations since they need minor separations. They can cross the foundation and bond to it. No heavy equipment is required and they can be installed in limited access areas and time-proven, economical and stable areas where bearing layer is within $15 \mathrm{~m}$ of deep. They are then hydraulically or pneumatically installed through a drive frame mounted on foundation wall. They can be cast-in concrete place by gravity or pressure, with recoverable or lost casing. Their capacities vary according to the diameter of micro-pile. In this case it is recommendable to form a continuity or wall of micro-piles because it notably improves the support of the wall foundation (Fig. 21). The disadvantage is the deficiency of local technology. However, the use of steel or prefabricate piles are not considered due to the lack of space for driving and the size of grain of the deep soil. 


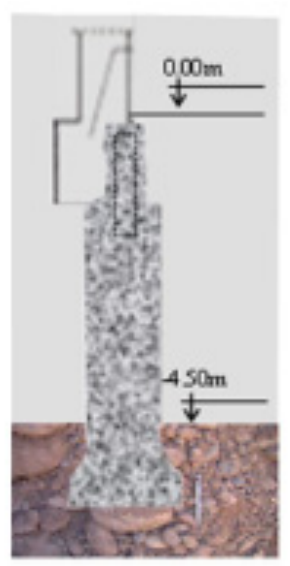

Fig. (20) Stiff foundation beam and pier.

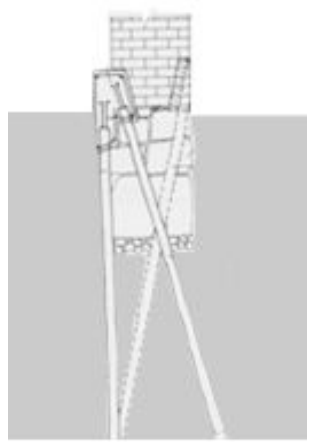

Fig. (21). Micro-piles.

The procedures for improving the geotechnical characteristics of the surrounding capacity are intended to improve or correct the soil bearing capacity. The decision requires a special investigation and a detailed assessment of the different technological solutions and their possibilities of success. The alternatives are very diverse such as injections (cement grout, resins, gel), fulfilling (bentonite, cement, polyurethane), deep compaction processes (viscous mortars) and jetgrouting technique, etc. The disadvantage is the deficiency of local technology (US Dep. Housing and Urban Development 1997) [7].

From a financial point of view, the most economic and technologically feasible rehabilitation of the foundations is the use of a lateral foundation beams and piers of reinforced concrete. From the geotechnical point of view, both proposals (1999 and 2010) are equal because the conditions of soils have not changed in the past decade.

To recover the monolithic of the masonry structure the use of grouting of cement or epoxi injections is suggested (Maldonado P10WCEE 1992) [9], considering the thickness of the cracks to recover the bond of masonry units and mortars. Depending on the thickness of the cracks may be stick across crack with pins and drilled dowels, especially the ones applied in the arches. Both proposals (1999 and 2010) are equal for recovering the monolithism of masonry but the cracking is increased.

The difference between proposals is in the type of intervention. The 1999 proposal established new reinforced con- crete columns and beams, but the professionals of preservation did not approve the intervention because it is very invasive (not reversible). To carry out the structural requests in 2010, it was proposed (FEMA 308 1999) [10]:

- To optimize the existing foundation, consolidating the foundation of gravel and debris by the inclusion of a ring beam of similar height of existing foundation and to excavate the piers until achieving the resistant stratum, situated at least at $-9 \mathrm{~m}$. If the conditions of neighbouring allow it, the foundation beam will be connected by means of metallic anchors between themselves or between the beam and the foundation localized in the mediating or the front.

- To arm a metallic truss in the top of the building, to tie in both directions the masonry walls by means of metallic beams anchored to the walls and metallic profiles, trussing the space to cover. This metallic truss is situated in such a way that the suspended ceiling does not leave it in evidence and allows it to be used for pipes of installations (electricity and conditioned air, Fig. 22).

- To transfer the effort of the structure to the foundations through metallic columns anchored in the structure of masonry walls and in the ring beam of foundation.

- The surface and subsurface drainage system is considered as a priority. For this, a new drainage system of the water with new and better materials should be done. For successful drainage the building should be protected from ground water migration through the soils adjacent to the foundation. The real state of the metal roof covering of the building is not adequate to protect the inside free of rain water, since it is in an advanced corrosion process. This forces to replace them to the shortness, being necessary to rebuild plumbing and gargoyles. The access of rain water to the closing walls on the first court with thermoplastic membrane must be resolved.

The structural computation has two branches: one of them is the formulation of a non linear finite element model, using isoperimetric elements with 8 nodes (3D), with constitutive models that simulate the non linear behavior of the masonry in order to verify the structural performance under distinct loads and conditions, already considering the existing damage of the structure with the settlements of foundations (Fig. 23) (Abaqus 6.4 2004) [11].

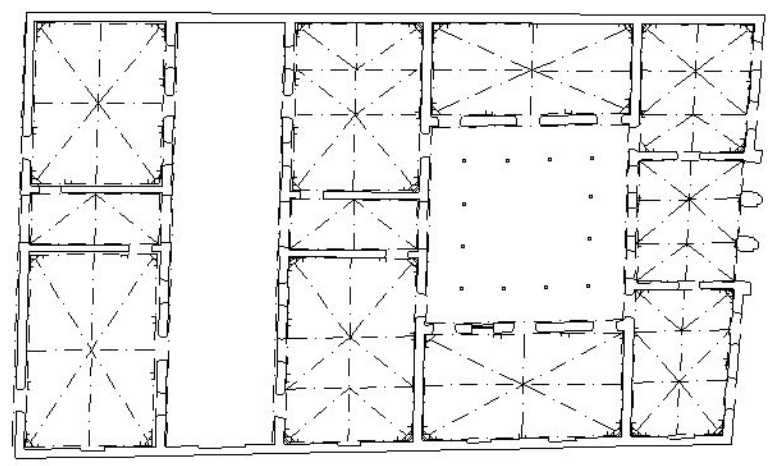

Fig. (22). Schematic upper truss reinforcement and columns. 


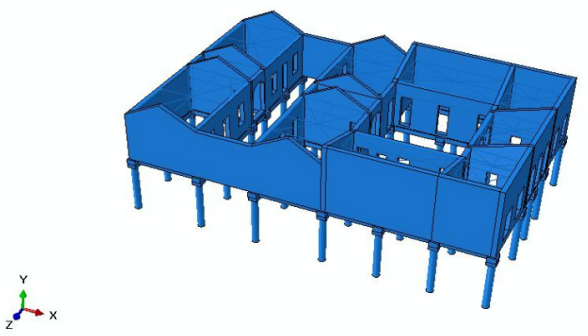

Fig. (23). Model of building.

The other branch is the structural analysis, in linear form, by means of finite elements software (SAP 2000) [12], which allows the design and verification of the proposed solution with different structural elements. The resistant structure of the building consists in thick masonry walls and columns. The roof covering is resolved by means of metallic truss that bear a wood framing and cane. To represent it some plates and bar elements were used, considering that these would properly simulate the structural appearances of interest in this study. It is very important to specify that the model only includes the structural aspects (Fig. 24).

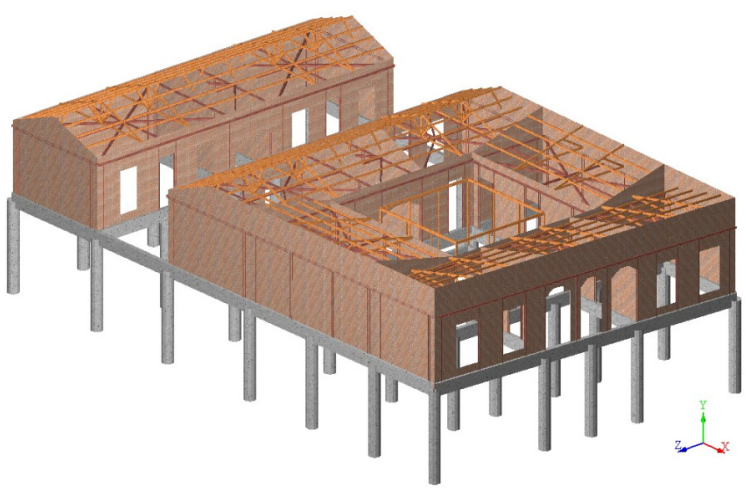

Fig. (24). Structural model of rehabilitation.

The adopted conditions of outline of the model were restrictions to the displacements in the 3 axis coordinates in the zones of contact with the foundation. The loads considered were: the dead loads, which are predominant in this type of buildings, and the equivalent seismic loads, just as regulations in force (Gobierno de Mendoza CCSR 1987) [13].

Fig. (25) can be considered as a representative result of the numerical study. The concentration of stress is associated to the intersection of shear walls and to the points of application of loads, points that will have to be reinforced locally, whereas the rest of the masonry walls are under maximum tensional stress. The existing structural system, particularly the masonry walls, maintains a level of stress under its capacity.

Fig. (26) presents the maximum stress for the combinations of loads that include the seismic load.

The upper truss fixed to the structure as indicated previously, is subjected to stress under its capacity as shown in Fig. (27).
For the determination of the seismic actions is applied the equivalent static method because the building has only one level and the application of dynamic method does not provide additional relevant information as regards the verification of structural safety against seismic actions. For determining the seismic coefficient, C, (Gobierno de Mendoza CCSR 1987) [13] were applied the following values:

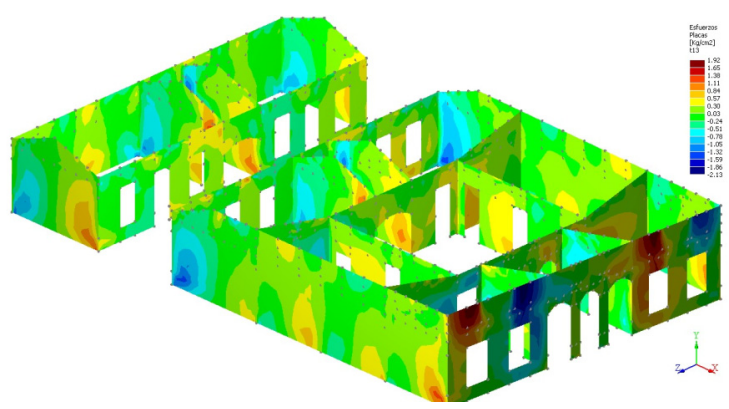

Fig. (25). Maximum stress in plates due to dead loads.

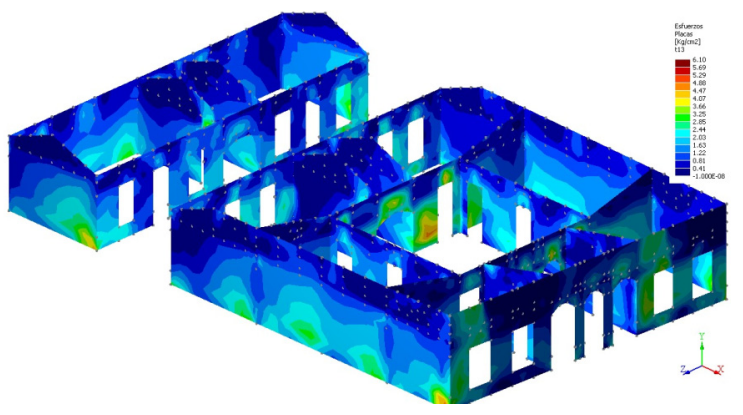

Fig. (26). Combined loads stress.

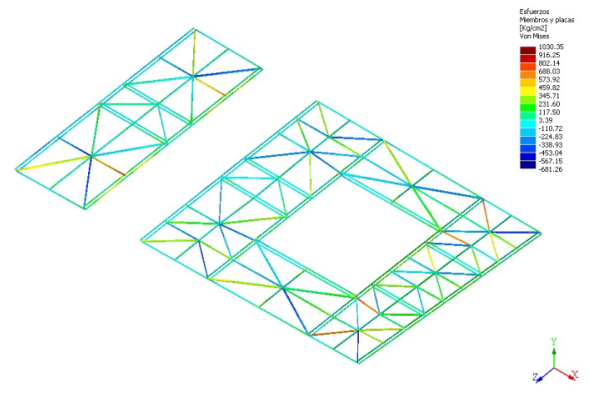

Fig. (27). Stress of truss at ceiling level.

- Mendoza seismic coefficient: $\mathrm{Co}=0.30$

- Destination: it considers the public use $\mathrm{d}=1.4$

- Ductility: masonry walls with $\mathrm{d}_{\mathrm{u}}=1.3$

- Tie: the truss at ceiling level ensures a link between all the structural planes, allowing the structure to work in horizontal actions in a monolithic way. The utilized value is $\mathrm{v}_{\mathrm{i}}=1.0$

- Soil: regarding soils' study, the adopted coefficient is based on shear wave velocity with coefficient $\mathrm{s}=1.2$ 
The coefficient $\mathrm{C}$ is the multiplication of $\mathrm{Co} * \mathrm{~d} *\left(\mathrm{~d}_{\mathrm{u}} * \mathrm{v}_{\mathrm{i}}\right) * \mathrm{~s}=0.6552$

To obtain a main accuracy in the determination of the actions, the coefficient $\mathrm{C}$ is applied in masonry walls as a multiplier of the dead loads. Whereas the seismic action generated by the masses of the roofing cover concentrated in the truss at ceiling level. The weight of the cover is of $95 \mathrm{~kg} / \mathrm{m}^{2}$ and for rehabilitation it is necessary to remove the mud layer to diminish weight. The analysis considers 12 states of combined loads for to calculate dimensions of metallic structures.

Table 3 presents the analysis of mass in front sector and the backward sector of building, values which are considered in seismic actions; and Table $\mathbf{4}$ shows the torsion evaluation due to seismic action. Table $\mathbf{5}$ presents the quantity and weight of cross sections of new structural elements.

Table 3. Weights of Sectors of Building

\begin{tabular}{|lcccccc|}
\hline Element & \multicolumn{2}{l}{ Front sector } & \multicolumn{4}{c|}{ Backward sector } \\
& $\begin{array}{c}\text { Weight } \\
\text { (t) }\end{array}$ & $\begin{array}{c}\mathbf{x} \\
(\mathbf{m})\end{array}$ & $\begin{array}{c}\mathbf{y} \\
(\mathbf{m})\end{array}$ & $\begin{array}{c}\text { Weight } \\
(\mathbf{t})\end{array}$ & $\mathbf{x}$ & $\mathbf{y}$ \\
& $\mathbf{( m )}$ & $(\mathbf{m})$ \\
\hline \hline Walls & 765.23 & 28.53 & 12.83 & 263.76 & 4.06 & 12.42 \\
Roof & 56.88 & 27.84 & 12.60 & 20.09 & 4.29 & 12.33 \\
Total & 822.19 & 28.49 & 12.81 & 283.80 & 4.07 & 12.42 \\
\hline
\end{tabular}

The numerical model indicates that the proposed rehabilitation gives the degree of necessary structural safety for the use. Chapter 8 of the CCSR' 87 [13] about "Modifications or repairs of existing buildings" evaluates the following aspects:

- Importance of the existing buildings (in 8.4.1.) corresponds to I.1. Important works: since it is a damaged structure with historical heritage value.

- Seismic resistant quality of the primitive building (in 8.4.2.) corresponds to C.4. Bad quality buildings: those that were not projected to the standard and which present signs of anomalous structural operation, poor execution or do not have a completed resistant system. Buildings do not adjust to the code in force at the moment of the erection or without seismic resistant previsions.

- Seismic resistant capacity of the primitive building (in 8.4.3.) corresponds to achieve S1: sufficient safety $\mathrm{r}>$ $100 \%$.

The CCSR'87 allows exceptions for works classified C4 such as: lack of closing ties in non bearing walls, lack of ties in the intersection of bearing walls, changes in the main separations that the standard regarding dimensions and maximum surface of the framed wall and the resistant capacity of the building and evaluation of the resistance reduced to the limits in article 8.6.

For the safety according S1 to the group I.1 results: repair of damages and complete adjustment to the code, or independent extensions and replacement program.
The existing masonry units for bearing masonry walls do not verify the minimum resistances required by the code in force based on the laboratory tests. The results obtained show that classification or the media compressive resistance is less than 7.5 $\mathrm{MPa}$. The mortars used in the building according to code in force correspond to very poor resistant compositions (Michelini P9IBBMC 1991) [14]. This resistant state implies the use of FEM for the performance of rehabilitated building and the measure of environmental vibrations when it will be repaired.

Table 4. Torsion Effects

\begin{tabular}{|lllll|}
\hline Axis & \multicolumn{2}{l}{ Front Sector } & \multicolumn{2}{l|}{ Backward sector } \\
\hline \hline & L (m) & Mt (t.m) & L (m) & Mt (t.m) \\
X & 25.00 & 1880.17 & 25.00 & 648.06 \\
$Z$ & 27.00 & 2030.57 & 8.50 & 220.34 \\
\hline
\end{tabular}

Table 5. Quantity of Materials for New Structural Elements

\begin{tabular}{|c|c|c|c|c|}
\hline $\begin{array}{l}\text { Name of Struc- } \\
\text { tural Element }\end{array}$ & Cross sections & & $\begin{array}{l}\text { Length } \\
\text { (m) }\end{array}$ & $\begin{array}{l}\text { Weight } \\
\text { (t) }\end{array}$ \\
\hline $\begin{array}{l}\text { Lateral beams both } \\
\text { faces }\end{array}$ & 2 UPN 140 & & 212 & 6.81 \\
\hline $\begin{array}{l}\text { Lateral beams one } \\
\text { face }\end{array}$ & UPN 140 & & 67 & 1.08 \\
\hline Truss & $\begin{array}{l}\text { Structural } \\
140 \times 140 \# 6.35\end{array}$ & tube & 106 & 2.74 \\
\hline Truss & $\begin{array}{l}\text { Structural } \\
100 \times 140 \# 4.0\end{array}$ & tube & 158 & 2.26 \\
\hline Truss & $\begin{array}{l}\text { Structural } \\
80 \times 140 \# 3.2\end{array}$ & tube & 193 & 2.04 \\
\hline Columns & UPN 180 & & 495 & 10.88 \\
\hline
\end{tabular}

Taking into consideration the conditions of maintenance, to delete the moisture in masonry walls it is proposed:

- to remove the existing plaster at 0.70 to $0.80 \mathrm{~m}$ and in the walls with waterproof plaster remove all the plaster.

- to drill holes in both faces of the walls affected by upward moisture in a depth of $2 / 3$ to $3 / 4$ of the thickness of the wall and in a separation, that will be function of the percentage of moisture in the moment of the execution of the work.

- to inject silicon resin such as flexible gel with pressure.

- to recover the plaster with hydrophobic character.

\section{CONCLUSIONS}

The actual effectiveness of the strengthening techniques shall be quantitatively proven, and the adopted solution shall guarantee compatibility, durability and reversibility. It is considered that the measure of environmental vibrations is a reliable method. 
Environmental conditions as well as maintenance program need to be carefully addressed to guarantee the service life.

Strengthening of historical and monumental buildings shall be justified only when is inevitable; the adopted strengthening technique shall be in compliance with the theory of restoration and local technologies and workmanship.

\section{ACKNOWLEDGMENTS}

This work has been part of Program PICTO RS 255 supported by the Technological National University of Argentina, National Agency for Promotion of Science and Technology of Argentina and Government of Mendoza. The authors want to thank the University staff: Sebastián Panella, Juan Carlos Palencia, Alfredo Cueto, Claudio Dagne, Sergio Acosta, Adrián Fantinel, Juan Pablo Cordone, Gerardo González del Solar, Diego Novillo y Marcelo Guevara, the professionals of preservation of Heritage Bureau of Province of Mendoza: Liliana Girini, Silvia Salustro, Mercedes Castro, Marcos Cannepuccia and Emanuel Fernández, and Gabriela Castellanos, that they had made the development of the research program possible.

\section{REFERENCES}

[1] F. Grementieri, C. Shmidt, Arquitectura, educación y patrimonio. Argentina 1600-1975. Buenos Aires: Pamplatina 2010.

[2] N. G. Maldonado, R. J. Michelini, Rehabilitación de un edificio de mampostería histórica en zona de elevado riesgo sísmico: un caso de estudio. Proceedings Engineering Congress 2000, 2000: pp. 2332.

[3] N. G. Maldonado, R. F. Michelini, N. F. Pizarro, I. A. Maldonado. Rehabilitación de un templo religioso en Mendoza: Un caso de estudio, Proceedings II Jornada Técnicas de Restauración y Conservación del Patrimonio, La Plata, 2003: 1- 10.

[4] A. Cismigiu, M. Cismigiu, The Seismic Phatology of Religion Related Buildings in Romania and their Treatement According to Article 10 of Venice Chart. Proceedings 11th World Conference on Earthquake Engineering, 1996: p. 582.

[5] N. G. Maldonado, M. E. Tornello. Report\#152: Base Isolator Confined Masonry, 2008. Available in http://world-housing.net/whereport1view.php?id=100170. [Access 07/01/2011]

[6] PLAXIS VB. V.8. 2005.

[7] U. S. Department of Housing and Urban Development. Foundations. The Rehab Guide. Norwalk, CT: Stteven Winter Associates, Inc., 1997; p. 1.

[8] B. Broms, "Design of Laterally Loaded Piles", ASCE J, vol. 91(SM3), pp. 79-99, 1965.

[9] N. G. Maldonado, L. A Olivencia, Techniques used to repair seismic-resistant masonry walls. Proceedings Tenth World Conference on Earthquake Engineering 1992: pp. 5384-9.

[10] FEMA 308, Repair of Earthquake Damaged Concrete and Masonry Walls. Federal Emergency Management Agency: ATC 1999.

[11] Abaqus V6.4-1. 2004.

[12] SAP 2000. Computers and Structures. 2000

[13] Gobierno de Mendoza. Código de Construcciones Sismorresistentes de la Provincia de Mendoza (CCSR) 1987.

[14] R. J. Michelini, N. G. Maldonado, Design and construction in seismic-resistant masonry standards in force in the Province of Mendoza, Argentina. Proceedings 9th International Brick/Block Masonry Conference 1991: pp. 903-912. 